International Journal of

Health, Medicine and

Nursing Practice

(IJHMNP)

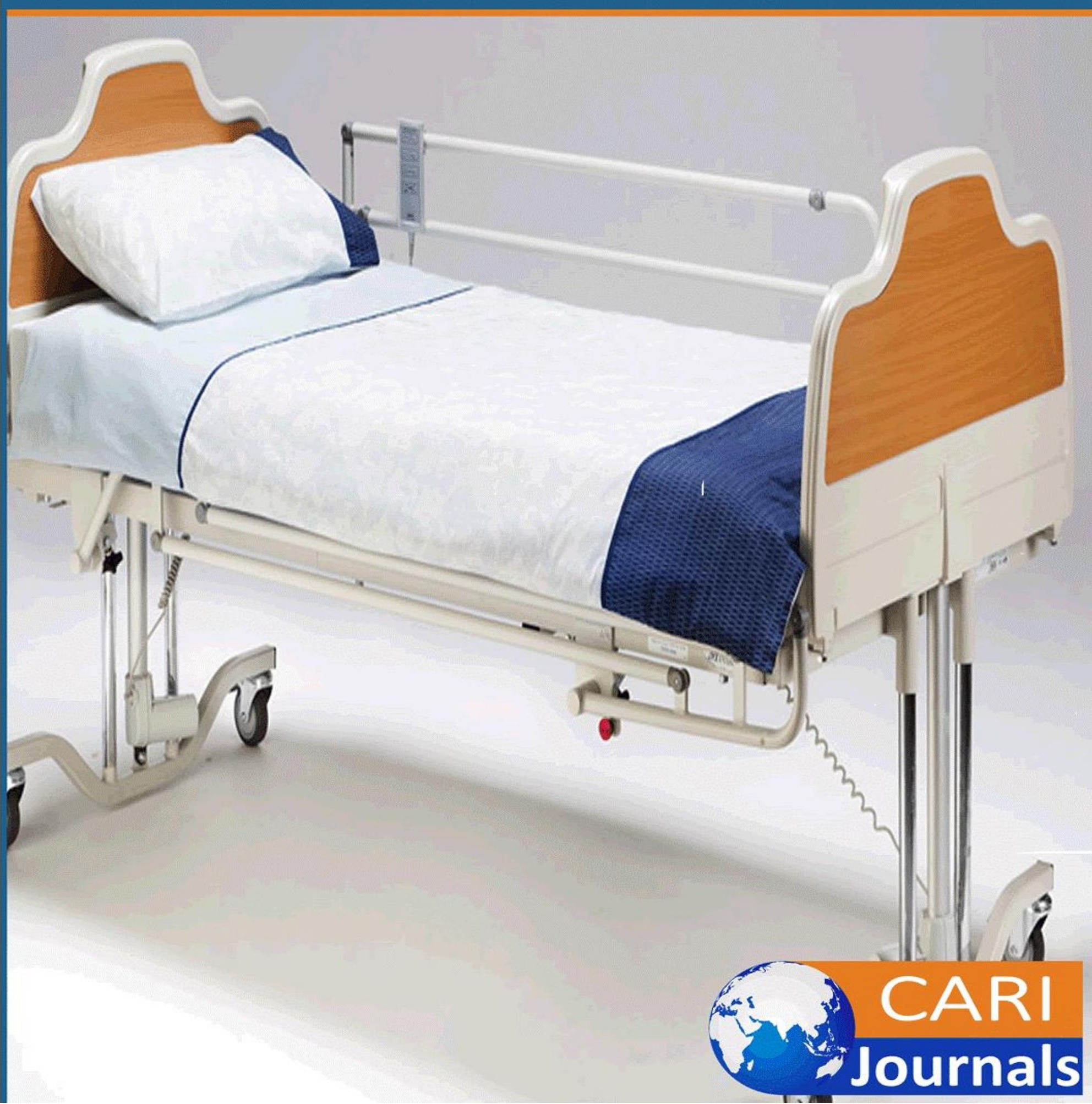




\title{
Knowledge Attitudes of Nurses towards the Use of Nursing Diagnosis in Clinical Practice
}

\author{
Kanwal, Kauser Parveen \\ Corresponding Authors Email: kbkanwal05@gmail.com
}

\begin{abstract}
Purpose: Assess the knowledge and attitude towards the nurses in the clinical practices to identify the level of awareness of nurses and improve their practice to minimize and prevent the risk of complications, as well as to improve patient outcomes.

Methodology: The cross sectional descriptive study design was used in the research. Target population was the staff nurses of the Govt hospital Lahore. The inclusion criteria was cardiac surgery ICU nurses in the hospital Lahore expressed the willingness of participation for this study were included after taking the consent. The sample size of the study was 100 nurses

Results: The study showed variations in the level of knowledge, attitude and practice of nurses, most of which reflected in their nursing practice their knowledge between the poor and the average. Many nurses have not been aware of the suggested practice and amounts have shown possibly of practice. The research also raised concern about all aspects of Nursing Diagnosis and highlighted the criteria for practice improvements and developed body of knowledge.

Unique contribution to theory, policy and practice: The study recommended the need for extensive improvements in the knowledge and practice of nurses by using the nursing diagnosis in the clinical for each nurse., It is the duty of nurses to develop a body of knowledge in their field of work, to promote the growth and personal development of local practice, to recognize knowledge gaps, to pursue appropriate training and resources, and to base all practice on facts.
\end{abstract}

Key words: Knowledge Attitudes, Nursing Diagnosis, Clinical Practice

\section{INTRODUCTION}

\section{Background}

The characteristic of nursing profession is to make judgments' through nursing diagnosis. The study on patient in clinical through practice of nursing diagnosis is to identify the difficulties advantages and disadvantages in data collection. The study suggests the practice of clinical diagnosis is improving the clinical practice through increasing the education of nursing staff and improving the practice of nursing diagnosis. (Seifert \& Grandusky, 1990)

The questionnaire was used for the data collection. Knowledge about nursing diagnosis is improved through the clinical work and study. The study shows the difficulties faced in clinical to lack of time and understandable language. The professional nurses assess actions, knowledge and 
International Journal of Health, Medicine and Nursing Practice

ISSN 2710-1150 (Online)

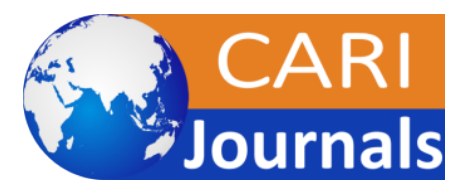

Vol. 3, Issue No. 3, pp 58- 68, 2021

WWW.carijournals.org

how to implement in the clinical areas all the skills. Through nursing diagnosis we organize knowledge and clinical decision.(Novotny - Dinsdale,1985)

The basic of the every nursing process is nursing diagnosis that is covered the implementation, planning and evaluation. The nursing diagnosis only focus on

Individual patient care and their health care problems the nurses do not differentiate among the patients. The nursing diagnosis increased the quality of care in this profession. (Sason, Vellsone, Kangasniemi 2017). This is very important to use the nursing diagnosis in the clinical practice. The use of nursing diagnosis is less because of lack of knowledge and skills in the nursing profession. Nursing diagnosis is believed to the care that we give to the patients show as evidence outcomes faced (Emirjona, K., Rezarta L., 2015)

Nursing diagnosis consists of patient quality of care, their stay in the house and discharge plane of any patient. Patient qualities of care depend of the nursing diagnosis. Nursing diagnosis provide the direction of the care for the patient. The nursing diagnosis is efficient effective method for the nursing skill full knowledge and provides efficient care and planning for the patient related health (Carpenito - Moyet, L.J.2013)

The nursing diagnosis second step of the nursing care plane and provide the needs of care to the patient as a direction. The study shows the use of nursing diagnosis in the clinical is a great achievement in the predict out comes (Kamberi F .2018). The study shows the systematic use of nursing diagnosis application in the clinical practice; provide the high quality nursing data in the profession. The use of the nursing diagnosis is efficiently performed in the many health care departments and using of these practices has proved the improvement in the nursing profession and also improve the quality of care in the all departments and have effective communication chance in the all health departments. The nursing diagnosis provides great responsibility and professionalism in the nursing profession (Alvaro, \& D "Agostino, 2017)

The nursing diagnosis is very valuable in the nursing profession especially in the clinical practices. The nursing diagnoses evaluate the patient progress and problem solving methods. The study shows the staff nurses who use nursing diagnosis in the daily life are most qualitative and economic care provides as compared those who are not using nursing diagnosis.(Sparks Ralph \& Taylor 2011)

The study have identify the benefits and barriers of implantation of their practices, the barriers are lack of staff, lack of facilities from the range of use ,time management, difficulty to continue the higher education lack of motivation in the clinical to apply in their daily routine of the nursing diagnosis (Whitley \& Gulanick, 1996).

The nursing diagnosis mostly used according to their patient problem and their way of life causative effect . Students are mostly unable to apply nursing diagnosis in the use knowledge and skills and also did not use skills that actually needed for the nursing diagnosis.(Hakans,V.B.2012)

The knowledge and skills are both to gather use in the nursing diagnosis. Attitude is defined the concussions level of the skills and knowledge towards the patient with active participation .The attitude show the position of work that leads the professional decisions (Johnson, L., Edward, K.L., 2017). The clinical practice is based on the standardized system of the nursing. The based on the 
actions that used towards the nursing diagnosis in the care of patients. The nursing diagnoses are helpful for the establishment of good health by applying the interventions, maintains of the disease process (Cardenas -Valladolid et al .,2012)

\section{Problem Statement}

After visiting the hospital, the aim of the study to found that nurses have, knowledge and attitude towards the use of nursing diagnosis in the clinical practices and it is the major problem of the hospital setting. Due to this reason the researcher decide to assess the knowledge and attitude towards the use of nursing diagnosis in the clinical practices in the Hospital of Lahore. The problem was prioritized by looking to various aspects like lack of time, lack of staff and work load. The nurses have poor knowledge and attitude towards the Patient Care. So considering all these aspects these particular problems was selected for project work.

\section{Purpose of Study}

Assess the knowledge and attitude towards the nurses in the clinical practices to identify the level of awareness of nurses and improve their practice to minimize and prevent the risk of complications, as well as to improve patient outcomes.

\section{Research Questions}

To assess nurses' knowledge for patient present in the ward or under care?

To assess nurses' practice for patient diagnosis in the clinical?

\section{Conceptual Definitions}

\section{Nursing diagnosis}

The nursing diagnosis is the part of the nursing process and clinical assessment of individual, family, or community experiences / responses to actual or potential health problems/life processes. Nursing diagnoses made after data collected from patient history (subjective data) and observation (objective data).

\section{Knowledge}

The information or awareness that needed for health restoration, prevention or health promotion.

\section{Practice}

Period arranged for the determination repeating and act developments are called practice. Practices are negative and positive (Mayer, 2018).

\section{Operational Definition}

\section{Nursing diagnosis}

Clinical judgment that focused on problem and prevent from risks and give opportunity to health promotion.

The nursing diagnosis is playing an important role in the nursing process and clinical judgment about individual. The nursing diagnosis depends on the assessment data that is collected from family, or community experiences / responses to actual or potential health problems/life processes. 
International Journal of Health, Medicine and Nursing Practice

ISSN 2710-1150 (Online)

Vol. 3, Issue No. 3, pp 58- 68, 2021

www.carijournals.org

\section{Knowledge}

Knowledge is the awareness of people of the hospital regarding Nursing Diagnosis. Time management and practice.

\section{Practice}

Doing something usual, usual or expected, or a way to do something.

\section{Significance of the Study}

Readers/researcher/students will be able to learn about the nursing diagnosis and as well as knowledge and practices in the clinical, Nurses after this study to consider the collection of Nursing diagnosis in the clinical practices and to associated time management and their hospital management. The hospital management will be able to take effective steps to enhance the quality of life by holding awareness workshops, seminar programs and educational program me, on the nursing diagnosis in the Hospital.

\section{CHAPTER TWO}

\section{LITERATURE REVIEW}

There are both international and national requests for nurses to use nursing diagnosis. However, nurses' attitude toward nursing diagnosis is very poor practice. Generally attitude of nurses towards the nursing diagnosis is positive. Mostly how are working from 10-15 years of experience in the clinical have most positive attitude. In the previous days the use of nursing diagnosis are not necessary but by the time it needs most in the clinical practices. (Ahtisham, Y. 2017)

The nursing knowledge is classified two categories' theoretical knowledge and practical skills. The use of nursing diagnosis in the clinical most effective for the standardized skills. Knowledge gained during clinical skills with study. The use of nursing diagnosis is requested in the clinical but most of the nurses are not agree to use the process.

Most of the nursing during the interview focused why they are not use nursing diagnosis in the clinical is lack of time. Findings suggest with use of skills we have to improve their education by use this in the clinical practices. This opportunity will increase the quality of care. Professional nurses assess the situation and take action with solving the problems from the clinical (Kamberi F. 2018).

This process is efficient and effective method for gaining the knowledge in the clinical practices. All over the world nursing process is used in the clinical and educational level. This process is consist of five steps assessment divided into two subjective data and objective data, nursing diagnosis, planning ,implementation interventions and evaluation (Emirjona, K., Rezarta L., Rudina Ç., Denada S. 2015)

The nursing diagnosis is the part of the nursing process and assessment of individual, in which data collected from family, or community experiences / responses to actual or potential health problems/life processes. The study shows will it clear the use of nursing diagnosis in the clinical is great predict for the best clinical practices. The use of the nursing diagnosis in largest scale in the clinical practices is the best contribution towards the evidence based practice. The study shows 
the use of nursing diagnosis in the clinical practices people who are using efficiently in the departments and the values have proved the quality of care.

On the international level the nursing diagnosis implementation on the standard practices improve the quality care of the patients. Also increase the efficiency in the work. Nursing diagnosis is the base of nursing process. The nursing diagnosis described the aim of the outcomes of nursing process (Kamberi F. 2018). The study shows the nurses who are using nursing diagnosis in the clinical are not qualitative rather than who are not using in their clinical practices.

A standard questionnaire used for the data collection of the nursing diagnosis . The lack of time and over work in the clinical is great difficulty to use the nursing process and applied the nursing diagnosis in our daily practices. The study is aimed to evaluate, perceptions and to identify the difficulties in the clinical practices. The implementation not on nursing diagnosis is one the gap between knowledge and skills. The difficulty to apply the nursing diagnosis is major problem in clinical is knowledge and awareness of the clinical practices. The literature shows the studies of nursing diagnosis are less applied in the clinical practices because of lack of staff and large range of patients. The data is collected from the questionnaire. Data is confidentially applied in the research.

\section{RESEARCH METHOLOGY}

\section{Research Design}

The cross sectional descriptive study design was used in the research.

\section{Data Analysis}

Arithmetical study was done through consuming the driver (SPSS) for window version 21.

\section{Target population}

Target population was the staff nurses of the Govt hospital Lahore

\section{Inclusion criteria}

The inclusion criteria was cardiac surgery ICU nurses in the hospital Lahore expressed the willingness of participation for this study were included after taking the consent.

\section{Exclusion criteria}

The exclusion criterion was the other medical staffs in the hospital do not show the willingness to participate in this study and all other people of the hospital were excluding in the study.

\section{Sampling Technique}

A non-probability sampling, techniques was used to collect the data.

\section{Sample Size}

Sample size was the 100 .

The sample size of the study was 100 nurses significant.

\section{Data collection techniques}


International Journal of Health, Medicine and Nursing Practice ISSN 2710-1150 (Online)

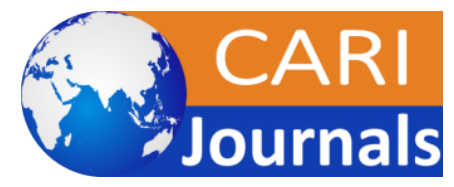

Vol. 3, Issue No. 3, pp 58- 68, 2021

WWW.carijournals.org

Assess various department of the hospital for the purpose of identifying problems. Assessment including questionnaires, observation, focus groups, interviews.

\section{Ethical considerations}

Permission obtains from the Department of the Lahore School of Nursing. All information of the participants were been protected by confidentiality Permission was taken from the hospital and consent form was signed before data collecting the data from the participants.

\section{Results}

The research analysis, data consist of 100 nurses in the hospital. The most of the nurses are diploma holders ( $\mathrm{N}$ of nurses 66). The degree holders in bachelor of nursing are 34 nurses. Only 30 nurses were working from less than one year. The number of 44 nurses was working from last 10 years and 26 were working above than 10 years. The $50 \%$ nurses have practice to use nursing diagnosis. The result shows the lack of use of nursing diagnosis due to lack of time and lack of knowledge in nurses. The most of the nurses not habitual in their profession for the use of nursing diagnoses.

Table1.Characteristics of the participants in the study

\begin{tabular}{|c|c|c|c|}
\hline variable & $\mathbf{N}$ & $\begin{array}{l}95 \% \text { CI(Lower- } \\
\text { upper) }\end{array}$ & $\begin{array}{l}\text { Current use of } N D \text { in } \\
\text { practice } P \text { values }\end{array}$ \\
\hline $\begin{array}{l}\text { Gender(female, } \\
\text { male) }\end{array}$ & $25-75$ & 1.6636-1.8364 & 0.4352 \\
\hline $\begin{array}{l}\text { Educational level } \\
\text { Certificate } \\
\text { Diploma } \\
\text { Degree }\end{array}$ & $\begin{array}{l}66 \\
34\end{array}$ & $2.3400-2.4345$ & 0.4761 \\
\hline $\begin{array}{l}\text { Additional } \\
\text { qualification } \\
\text { Yes } \\
\text { No }\end{array}$ & $\begin{array}{l}47 \\
53\end{array}$ & $1.4305-1.6295$ & 0.5016 \\
\hline $\begin{array}{l}\text { Age of respondents } \\
<25 \\
25-30 \\
31-35 \\
36-40 \\
41-45 \\
45-50\end{array}$ & $\begin{array}{l}31 \\
47 \\
21 \\
1\end{array}$ & $1.7716-2.0628$ & 0.7478 \\
\hline
\end{tabular}

Table1.Characteristics of the participants in the study 
International Journal of Health, Medicine and Nursing Practice ISSN 2710-1150 (Online)

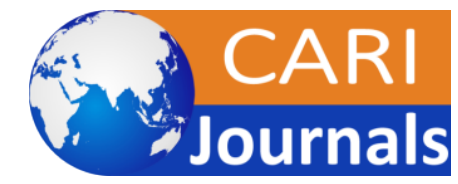

Vol. 3, Issue No. 3, pp 58- 68, 2021

WwW.carijournals.org

\begin{tabular}{|l|l|l|l|}
\hline Years served in the & & & \\
unit & $\mathbf{3 0}$ & $\mathbf{1 . 9 6 0 0 - 1 . 8 1 1 0}$ & $\mathbf{0 . 7 5 1 0}$ \\
$<1$ Year & $\mathbf{4 4}$ & & \\
6-10 Years & $\mathbf{2 6}$ & & \\
$>$ 10 Years & & & \\
\hline Current practic- & $\mathbf{5}$ & $\mathbf{3 . 7 5 4 0 - 4 . 4 4 6 0}$ & .17437 \\
Pathology & $\mathbf{2 3}$ & \\
-Intensive care & $\mathbf{1 6}$ & & \\
-Emergency & $\mathbf{0}$ & & \\
& $\mathbf{2 5}$ & & \\
& $\mathbf{3 1}$ & & \\
\hline
\end{tabular}

Table 2. Knowledge of nursing diagnosis

\begin{tabular}{|l|l|l|}
\hline \multicolumn{1}{|c|}{ Variable } & n & \multicolumn{1}{|c|}{$\%$} \\
\hline Knowledge of nursing diagnosis & 67 & 67 \\
Yes & 33 & 100 \\
No & & \\
\hline If yes, from whom you gained this knowledge & 55 & 55 \\
At work or various training & 45 & 100 \\
Program of Nursing high school & & 52 \\
\hline In which past roles was it an expectation that you & 52,48 & 100 \\
diagnosis patient problems using nursing diagnoses & & 51 \\
In at least one practice setting as a nurse practitioner & 100 \\
In at least one practice setting during the professional practice. & 55,45 & \\
As a nursing student. & & 67 \\
\hline Do you nursing diagnosis in your current clinical practice. & 50 & 100 \\
\hline
\end{tabular}

Table 3. Attitude towards the nursing diagnosis

\begin{tabular}{|l|l|l|l|}
\hline Variable & Gender* & Means & SD** \\
\hline
\end{tabular}


International Journal of Health, Medicine and Nursing Practice ISSN 2710-1150 (Online)

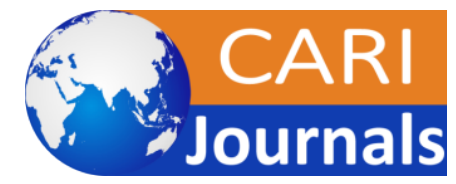

Vol. 3, Issue No. 3, pp 58- 68, 2021

Www.carijournals.org

\begin{tabular}{|c|c|c|c|}
\hline $\begin{array}{l}\text { Perceived difficulties due to the lack of } \\
\text { knowledge of nursing diagnoses }\end{array}$ & $\begin{array}{l}\mathbf{F} \\
\mathbf{M}\end{array}$ & & \\
\hline Perceived difficulties due to the lack of time & $\begin{array}{l}\mathbf{F} \\
\mathbf{M}\end{array}$ & 1.4600 & .50091 \\
\hline $\begin{array}{l}\text { Perceived difficulties due to the lack of } \\
\text { administrative support }\end{array}$ & $\begin{array}{l}\mathbf{F} \\
\mathbf{M}\end{array}$ & 1.4300 & .49757 \\
\hline $\begin{array}{l}\text { Perceived difficulties due to the lack of } \\
\text { physician support }\end{array}$ & $\begin{array}{c}\mathbf{F} \\
\mathbf{M}\end{array}$ & 1.3800 & .48783 \\
\hline $\begin{array}{l}\text { Perceived difficulties due to the lack of peers } \\
\text { (nurse) support }\end{array}$ & $\begin{array}{l}\mathbf{F} \\
\mathbf{M}\end{array}$ & 1.3800 & .48783 \\
\hline $\begin{array}{l}\text { Perceived difficulties due to the lack of co- } \\
\text { workers support }\end{array}$ & $\begin{array}{c}\mathbf{F} \\
\mathbf{M}\end{array}$ & 1.4000 & .49237 \\
\hline $\begin{array}{l}\text { Perceived difficulties due to the lack of clarity } \\
\text { of nursing diagnosis language }\end{array}$ & $\begin{array}{l}\mathbf{F} \\
\mathbf{M}\end{array}$ & 1.5300 & .50181 \\
\hline $\begin{array}{l}\text { Perceived difficulties due to the lack of } \\
\text { reimbursement for the use of nursing } \\
\text { diagnoses }\end{array}$ & $\begin{array}{l}\mathbf{F} \\
\mathbf{M}\end{array}$ & 1.3400 & .47610 \\
\hline
\end{tabular}

Table4.Difficulties in clinical practice

\begin{tabular}{|l|c|c|c|}
\hline \multicolumn{1}{|c|}{ variables } & Gender & Means & SD \\
\hline $\begin{array}{l}\text { Difficulties due to the lack of knowledge of nursing } \\
\text { diagnoses }\end{array}$ & F & & \\
\hline Difficulties due to lack of time & F & $\mathbf{1 . 5 3 0 0}$ & $\mathbf{5 0 1 6 1}$ \\
\hline Difficulties due to the lack of administrative support & F & $\mathbf{1 . 3 7 0 0}$ & .48524 \\
\hline
\end{tabular}


International Journal of Health, Medicine and Nursing Practice ISSN 2710-1150 (Online)

Vol. 3, Issue No. 3, pp 58- 68, 2021

$\underline{\text { www.carijournals.org }}$

\begin{tabular}{|l|c|c|c|}
\hline & M & 1.4700 & .50161 \\
\hline Difficulties due to lack of physicians support & F & & \\
& M & 1.3100 & .46482 \\
\hline Difficulties due to the lack of peers (nurse) support & F & & \\
\hline Difficulties due to the lack of co- worker support & F & 1.4600 & .50091 \\
\hline $\begin{array}{l}\text { Difficulties due to the lack of clarity of nursing } \\
\text { diagnosis language }\end{array}$ & F & 1.4500 & .50000 \\
\hline $\begin{array}{l}\text { Difficulties due to the lack of reimbursement for the use } \\
\text { of nursing diagnoses }\end{array}$ & F & $\mathbf{1 . 3 8 0 0}$ & .48783 \\
\hline
\end{tabular}

Table 5.Practices towards the nursing diagnosis

\section{Discussion}

The study result shows the knowledge, attitude and practices of the nurses in the clinical areas. The $25 \%$ nursing diagnosis used in intensive care, $23 \%$ in surgery and $31 \%$ used of nursing diagnosis in the emergency department. Table 1 is show demographic data of the sample size. Table 2 shows the knowledge of the nursing diagnosis in the data analysis. The number of 55\% nurses aware from the knowledge of nursing diagnosis in the training schools of the nursing population. Only $50 \%$ nurses have knowledge. $\mathrm{SD}=.47258$ Tables 3 shows the attitude of the use of the nursing diagnosis. Difficulties to use of nursing diagnosis in the clinical due to the lack of the time, lack of the knowledge, clarity in the language, and lack of coworkers support. Table 4 shows the difficulties in the use of nursing diagnosis in the clinical practice. The use of nursing diagnosis in the can improve with the use of standardized practice in the clinical area. The benefits of nursing diagnosis are to develop a critical thinking in the nursing practice. The result shows the consideration of the use nursing diagnosis in the clinical practice. Table 5 is described the practice of the nursing diagnosis in the clinical. In the clinical to improve the nursing process MEAN $=1.4200$ and $\mathrm{SD}=.49604$. Some nurses have knowledge about nursing diagnosis but clinical issues lack of cooperation with each other. Perceived difficulties due to lack of support of coworkers the $\mathrm{SD}=49237$. The lack of administrative support $\mathrm{SD}=.49757$. The literature review shows the use of nursing diagnosis in the clinical practice improve the high quality of nursing care and out comes from patient and hospital care. The following of standardized practice in the clinical can improve the nursing care and maintain to developing the critical thinking in the nurses.

\section{Conclusion}


International Journal of Health, Medicine and Nursing Practice ISSN 2710-1150 (Online)

Vol. 3, Issue No. 3, pp 58- 68, 2021

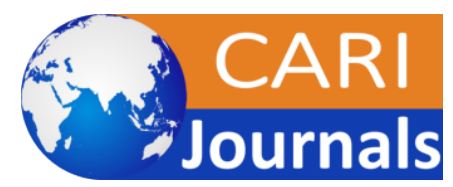

WWW.carijournals.org

The study showed variations in the level of knowledge, attitude and practice of nurses, most of which reflected in their nursing practice their knowledge between the poor and the average. Many nurses have not been aware of the suggested practice and amounts have shown possibly of practice. The research also raised concern about all aspects of Nursing Diagnosis and highlighted the criteria for practice improvements and developed body of knowledge. Any of these issues are improvable and when they occur, they must be handled correctly and appropriately. The practice is poor due to lack of time, lack of staff and poor management.

\section{Recommendation}

The study recommended the need for extensive improvements in the knowledge and practice of nurses by using the nursing diagnosis in the clinical for each nurse., It is the duty of nurses to develop a body of knowledge in their field of work, to promote the growth and personal development of local practice, to recognize knowledge gaps, to pursue appropriate training and resources, and to base all practice on facts.

\section{Limitations}

This is my first attempt to write and perform research studies, so study is not productive and quick because of this. People were not cooperative, when data collection faced some hospital difficulties: they did not have time to answer my questions and declined to respond.

\section{References}

Ahtisham, Y. (2017). The nursing process and patient teaching. Nursing Made Incredibly Easy, 15(6), 13-16. doi:10.1097/01.nme.0000525549.21786.b5

Carpenito-Moyet, L. J. (2010). Invited paper: Teaching nursing diagnosis to increase utilization after graduation. International Journal of Nursing Terminologies

Carpenito-Moyet, L. J. (2013). Nursing diagnosis: Application to clinical practice (14 ${ }^{\text {th }}$ Ed.). Philadelphia, USA: Lippincott Williams \& Wilkins.

Emirjona, K., Rezarta L., Rudina Ç., Denada S. (2015). Core principles of nursing. Lecture notes (1st Ed.). Vlore, Albania: Triptik.

Kamberi F. (2018). Nursing diagnosis. Lecture notes (1st Ed.). Vlore Albania: Triptik. Håkans, V. B. (2012). Nurses' perception of nursing diagnosis. NI 2012: $11^{\text {th }}$ International Congress on Nursing Informatics, 2012, June 23-27. Montreal, Canada. Retrieved from

Paans, W., Nieweg, R. M. B., van der Schans, C. P., \& Sermeus, W. (2011). What factors influence the prevalence and accuracy of nursing diagnoses?

Factors influence the prevalence and accuracy of nursing diagnoses Clinical Nursing, 20(17), 2386-2403. doi:10.1111/j.1365-2702.2010.03573.

Sparks Ralph, S., \& Taylor, C. M. (2011). Sparks and Taylor's nursing diagnosis pocket guide. Philadelphia, USA: Lippincott Williams \& Wilkins. 
International Journal of Health, Medicine and Nursing Practice ISSN 2710-1150 (Online)

Vol. 3, Issue No. 3, pp 58- 68, 2021

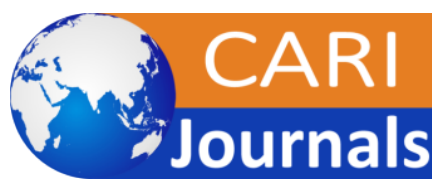

www.carijournals.org

Whitley, G. G., \& Gulanick, M. (1996). Barriers to the use of nursing diagnosis language in clinical settings. International Journal of Nursing Terminologies and Classifications, 7(1), 25-32. doi:10.1111/j.1744-618x.1996.tb00523.x

1. Gonza'lez EL, Johansson S, Wallander MA, Garc1 